\title{
Discontinuation of continuous positive airways pressure in infants with respiratory distress syndrome
}

\author{
THOMAS HEGYI AND I. MARK HIATT \\ Division of Perinatology, Monmouth Medical Center, and the Department of Pediatrics, \\ Hahnemann Medical College and Hospital of Philadelphia
}

SUMMARY Unexpected stability of arterial oxygen and carbon dioxide tensions occurred in infants recovering from respiratory distress syndrome (RDS) on the abrupt withdrawal of CPAP at $6 \mathrm{cmH}_{2} \mathrm{O}$ pressure. 30 preterm infants (birthweights $880-3200 \mathrm{~g}$ gestational ages 29-38 weeks) were treated at a mean age of 10 hours and for a mean duration of 62 hours. CPAP was stopped when $\mathrm{F}_{1} \mathrm{O}_{2}$ requirement fell below $0 \cdot 3$, and stable $\mathrm{Po}_{2}$ was maintained for 4 hours. Discontinuation of CPAP at $6 \mathrm{cmH}_{2} \mathrm{O}$ resulted in a mean change in $\mathrm{Po}_{2}$ from 66 to 64 $\mathrm{mmHg}(8 \cdot 8$ to $8.5 \mathrm{kPa})$ and a mean change in $\mathrm{PCO}_{2}$ from 41 to $40 \mathrm{mmHg}(5 \cdot 4$ to $5 \cdot 3 \mathrm{kPa})$. We conclude that this population of infants suffering from moderate RDS tolerated the abrupt withdrawal of CPAP, and that gradual reduction of pressure was unnecessary.

It is now over 7 years since CPAP was recognised as an effective mode of treatment for infants suffering from respiratory distress syndrome (RDS) (Gregory et al., 1971). However there are still many unanswered questions before the maximum benefit-risk ratio is attained: the best time and mode for instituting treatment, the most efficient pressures, the techniques for monitoring complex physiological processes, and the optimal time and method for stopping treatment. With regard to this last, a prospective trial was designed to determine the effect on arterial bloodgas tensions of removing CPAP without the generally accepted weaning procedure (Llewellyn and Swyer, 1973; Krouskop et al., 1975; John et al., 1976; Stark and Taeusch, 1977).

\section{Patients and methods}

During the 7-month period from 1 July 1977 to 31 January 1978, 41 infants suffering from RDS were admitted to the neonatal intensive care unit. Of these infants, 30 required treatment with CPAP as the sole form of support, while 11 were treated with mechanical ventilation. The former group of infants comprised the study group.

CPAP was delivered by a nasal prong device (Wung et al., 1975) at a pressure of $6 \mathrm{cmH}_{2} \mathrm{O}$. This applied pressure measured at the nares was kept constant and $\mathrm{F}_{\mathrm{I}} \mathrm{O}_{2}$ was altered throughout the course of treatment in order to maintain $\mathrm{PO}_{2}$ in the 50-80 $\mathrm{mmHg}$ range. The criteria for stopping CPAP were: ambient oxygen requirement of 0.3 or less to maintain $\mathrm{Po}_{2}$ above $50 \mathrm{mmHg}$, a stable $\mathrm{Po}_{2}$ at this level of support for 4 hours, and the absence of clinical signs of respiratory distress. Arterial blood samples were drawn from the umbilical catheter about 20 or 30 minutes before and after the withdrawal of CPAP and measured on an IL oxygen analyser (Instrumentation Laboratories: Lexington, Mass.).

The mean birthweight of the infants was $1920 \mathrm{~g}$ (range 800 to 3200 ) and the mean gestational age 34 weeks (range 29 to 38). Nine infants weighed $<1500 \mathrm{~g}$, 9 were between 1500 and $2000 \mathrm{~g}$, and 12 were $>2000 \mathrm{~g}$.

RDS was determined by $x$-ray and clinical evaluation to be of moderate severity. $\mathrm{A}-\mathrm{aDo}_{2}$ values were calculated at the time that treatment with CPAP was started for a precise assessment of the disease. The $\mathrm{A}-\mathrm{aDo}_{2}$ before treatment was $217+110 \mathrm{mmHg}$ (mean $\pm \mathrm{SD}$ ). $70 \%$ of the $\mathrm{A}-\mathrm{aDo}_{2}$ values were between 100 and $300 \mathrm{mmHg}$, and $23 \%$ were between 300 and $600 \mathrm{mmHg}$.

\section{Results}

CPAP was begun at a mean age of $10 \pm 10$ hours (mean $\pm \mathrm{SD}$ ). The mean duration of CPAP was 62 hours, SD 36. 14 infants reached the criteria for withdrawal by 48 hours whereas the remainder required 48 to 160 hours to reach this goal.

The response of the arterial blood-gases to the removal of CPAP was evaluated at a $\mathrm{F}_{1} \mathrm{O}_{2}$ of $0 \cdot 26 \pm$ 0.04 at an $\mathrm{A}-\mathrm{aDo}_{2}$ of $71 \pm 28 \mathrm{mmHg}$. The $\mathrm{Po}_{2}$ on CPAP was $66 \pm 9 \mathrm{mmHg}$ and off CPAP it was $64 \pm$ $10 \mathrm{mmHg}(\mathrm{P}>0.5)$. The $\mathrm{PCO}_{2}$ was $41 \pm 7 \mathrm{mmHg}$ before CPAP withdrawal and $40 \pm 8 \mathrm{mmHg}$ after $(\mathrm{P}>0 \cdot 5)$. The distribution of $\mathrm{PO}_{2}$ and $\mathrm{PCO}_{2}$ values before and after CPAP was comparable (Figure). None of the infants needed to return to CPAP after it had been stopped.

Examination of the individual responses showed that $10 \mathrm{Po}_{2}$ values increased and 20 decreased, while 


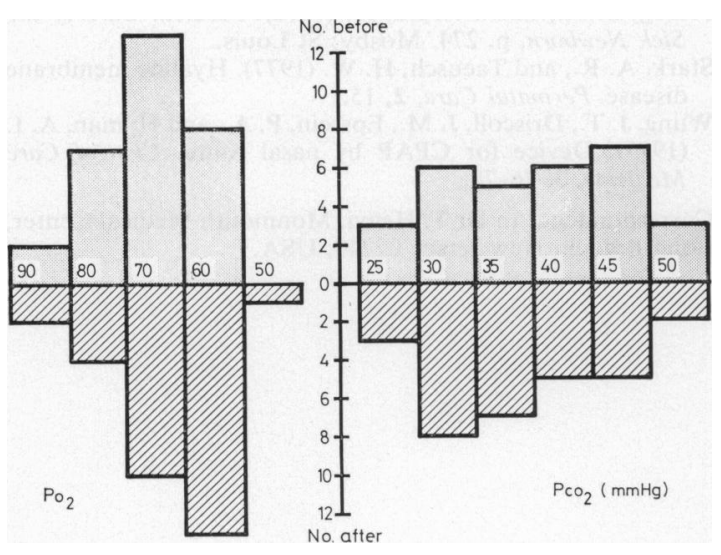

Figure Distribution of $\mathrm{PO}_{2}$ and $\mathrm{PCO}_{2}$ before and after abrupt withdrawal of CPAP.

$9 \mathrm{PCO}_{2}$ levels increased and 18 decreased. In the data analysis a $10 \mathrm{mmHg}$ change in $\mathrm{PO}_{2}$ was assumed to be within normal limits of $\mathrm{Po}_{2}$ variability, as suggested by observations during continuous monitoring with the transcutaneous oxygen electrode (Dangman et al., 1976). Under these conditions 20 $\mathrm{PO}_{2}$ values remained stable while 5 increased and 5 decreased. The $\mathrm{PCO}_{2}$ before withdrawal was significantly lower in those infants in whom the $\mathrm{Po}_{2}$ increased than in the other two groups $(P<0.05)$. $A$ further comparison of these subgroups (Table) showed no significant differences with respect to birthweight, age at start, $\mathrm{A}-\mathrm{aDo}_{2}$ at start, duration of treatment, and the $\mathrm{PCO}_{2}$ response to withdrawal.

The negative correlation between $\mathrm{Po}_{2}$ before withdrawal and the $\mathrm{Po}_{2}$ response remained significant in the analysis of all variables $(P<0 \cdot 05)$. In addition, a significant positive correlation was noted between duration of treatment and $\mathrm{PCO}_{2}$ before CPAP withdrawal $(P<0 \cdot 05)$. No correlation was found between the $\mathrm{Po}_{2}$ and $\mathrm{PCO}_{2}$ responses and birthweight, gestational age, age and $\mathrm{A}-\mathrm{aDo}_{2}$ at the start, and $\mathrm{F}_{\mathrm{I}} \mathrm{O}_{2}$ and $\mathrm{A}-\mathrm{aDO}_{2}$ at the time of CPAP removal.

Table Comparison of the $\mathrm{PO}_{2}$ response subgroups

\begin{tabular}{lccc}
\hline & $\begin{array}{c}\text { Increased } \\
(n=5)\end{array}$ & $\begin{array}{c}\text { Unchanged } \\
(n=20)\end{array}$ & $\begin{array}{c}\text { Decreased } \\
(n=5)\end{array}$ \\
\hline Birthweight (mean $\pm \mathrm{SD}$ & & & \\
g) & $2240 \pm 790$ & $1805 \pm 558$ & $2080 \pm 348$ \\
Age at start (hours) & $6 \pm 4$ & $10 \pm 8$ & $16 \pm 16$ \\
$\mathrm{A-aDo}_{2}$ start (mmHg) & $210 \pm 90$ & $238 \pm 123$ & $197 \pm 70$ \\
$\mathrm{PO}_{2}$ prior $\left(\mathrm{mmHg}^{2}\right)$ & $57 \pm 4^{*}$ & $67 \pm 8$ & $76 \pm 4$ \\
Change in $\mathrm{PCO}_{2}(\mathrm{mmHg})$ & $-4 \pm 6$ & $-1 \pm 5$ & $3 \pm 4$ \\
\hline
\end{tabular}

Conversion: traditional to SI units- $\mathrm{A}-\mathrm{aDo}{ }_{2}, \mathrm{Po}_{2}$, and $\mathrm{PCO}_{2} 1 \mathrm{mmHg} \approx$ $0.133 \mathrm{kPa}$.

${ }^{*} \mathbf{P}<0.05$.

\section{Discussion}

Before this prospective trial, the procedure for stopping CPAP in the treatment of infants with RDS had not been critically assessed, although textbooks (Llewellyn and Swyer, 1973; Pierog and Ferrara, 1976) and papers (Krouskop et al., 1975; Stark and Taeusch, 1977) have suggested that weaning is the optimal method of CPAP removal.

The results of this study show that the abrupt removal of CPAP did not place any infant in a state of hypoxia or hyperoxia. The possibility that the criteria for stopping CPAP resulted in some infants being treated longer than necessary is indicated by the correlations. The positive correlation between duration and $\mathrm{PCO}_{2}$ before withdrawal as well as the negative one between $\mathrm{Po}_{2}$ before withdrawal and the $\mathrm{Po}_{2}$ response, suggest that towards the end of treatment CPAP may have had a deleterious effect. These results suggest that in some infants recovering from RDS, prolonged use of constant distending pressure can cause slight $\mathrm{Po}_{2}$ decrease and $\mathrm{CO}_{2}$ retention. This observation has previously been reported by Nelson et al. (1977). Therefore abrupt withdrawal could have been completed earlier in the course of recovery.

Several hypotheses may be considered as possible explanations for the blood-gas responses to CPAP withdrawal. The removal of a constant distending pressure may result in a new ventilation perfusion relationship or in the initiation of compensatory mechanisms by the infant.

We conclude that our population of infants recovering from moderate $R D S$ tolerated the abrupt removal of CPAP, so that gradual reduction of pressure was unnecessary. In some infants prolonged use of CPAP had deleterious effects.

We thank Drs William Fox, Leonard Indyk, and L. Stanley James for suggestions, Mr John Kennedy for statistical analysis, and Mrs Nancy Gallo for secretarial assistance.

\section{References}

Dangman, B. C., Hegyi, T., Hiatt, I. M., Indyk, L., and James, L. S. (1976). The variability of $\mathrm{Po}_{2}$ in newborn infants in response to routine care (abstract). Pediatric Research, 10, 422.

Gregory, G. A., Kitterman, J. A., Phibbs, R. H., Tooley, W. H., and Hamilton, W. K. (1971). The treatment of idiopathic respiratory distress syndrome with continuous positive airway pressure. New England Journal of Medicine, 284, 1333-1340.

John, E., Thomas, D. B., and Burnard, E. D. (1976). Influence of early introduction of continuous positive pressure breathing on the course of hyaline membrane disease. Australian Paediatric Journal, 12, 276-280.

Krouskop, R. W., Brown, E. G., and Sweet, A. Y. (1975). The early use of continuous positive airway pressure in the 
treatment of idiopathic respiratory distress syndrome. Journal of Pediatrics, 87, 263-267.

Llewellyn, A., and Swyer, P. (1973). Assisted ventilation. In Care of the High Risk Neonate, p. 154. Edited by M. H. Klaus and A. A. Fanaroff. Saunders: Philadelphia.

Nelson, R. M., Egan, E. A., and Eitzman, D. V. (1977). Increased hypoxemia in neonates secondary to the use of continuous positive airway pressure. Journal of Pediatrics, 91, 87-91.
Pierog, S. H., and Ferrara, A. (1976). Medical Care of the Sick Newborn, p. 274. Mosby: St Louis.

Stark, A. R., and Taeusch, H. W. (1977). Hyaline membrane disease. Perinatal Care, 2, 15.

Wung, J. T., Driscoll, J. M., Epstein, P. A., and Hyman, A. I. (1975). Device for CPAP by nasal route. Critical Care Medicine, 3, 76-78.

Correspondence to Dr T. Hegyi, Monmouth Medical Center, Long Branch, New Jersey 07740, USA.

\section{Change of reference style}

From January 1980, the Archives will change its style for citing references and will follow the number system. We are making this change in order to conform with the 'Vancouver style' of uniform requirements for manuscripts submitted to biomedical journals.

Previously the Archives has used the Harvard reference system. Its advantages and disadvantages compared with those of the number system have seemed evenly balanced, but the editors have been aware of the burden imposed on authors and their secretaries by the different styles which different journals require. Therefore, with the unanimous agreement of the editorial committee, we have decided to support a move whereby a large - and increasing-number of major medical journals will accept manuscripts presented in one agreed style.

The system numbers references consecutively in the order in which they are first mentioned in the text. References are identified in the text by arabic numerals. For further details see instructions to authors inside the front cover, and the references cited. ${ }^{1,2}$

From now onwards all manuscripts submitted should accord with the new style.

1 International Steering Committee of Medical Editors. Uniform requirements for manuscripts submitted to biomedical journals. $\mathrm{Br}$ Med $J$ 1979; 1 : 533-535.

2 Lancet. The Vancouver style. Uniform requirements for manuscripts submitted to biomedical journals. Lancet 1979; 1 : 429-430. 